\title{
CAPITAL SOCIAL E DESEMPENHO INSTITUCIONAL NO COLEGIADO TERRITORIAL DA BORBOREMA, PARAÍBA
}

$\overline{\text { Márcio Caniello, Marc Piraux, Valério Veríssimo de Souza Bastos }}$

\section{RESUMO}

Num processo de inovação institucional que culminaria com a criação do Programa Territórios da Cidadania em 2008, o governo brasileiro reconfigurou, a partir de 2003, o panorama das políticas públicas para a agricultura familiar no país, adotando o "enfoque territorial de desenvolvimento rural", efetivado por meio da criação de colegiados participativos paritários destinados a implementarem a "gestão social" dos recursos públicos ofertados pelo Orçamento Geral da União para projetos de investimento e custeio em "instâncias territoriais", isto é, conjuntos de municípios agrupados por características identitárias comuns. Este trabalho visa analisar a dinâmica da gestão social no território da Borborema, na Paraíba, considerando que ele possui um histórico de dinâmicas sociais que favoreceram a emergência de um movimento social forte e a constituição de um combativo Polo Sindical, ou seja, que o território apresentava um "capital social" relativamente consolidado antes mesmo da implantação do colegiado. Neste sentido, procuramos entender por que, apesar do evidente avanço das dinâmicas participativas e de suas repercussões positivas no ambiente sociopolítico local, as práticas territoriais apresentam, contudo, um "desempenho institucional" abaixo das expectativas, vis-a-vis aos poucos projetos de investimento efetivamente implantados entre 2003 e 2010.

Palavras-chave: Teoria; Pesquisa; Metateoria.

\section{ABSTRACT}

SOCIAL CAPITAL AND INSTITUTIONAL PERFORMANCE AT THE BORBOREMA TERRITORIAL COLEGIATE- PARAIBA STATE, BRAZIL

The Brazilian government has promoted, since 2003, public policies for small-scale farming, adopting a "territorial approach for rural development". The creation of Citizenship Territories in 2008 is the high point of this process of institutional innovation. Creation of participatory forums, promoting a closer partnership between civil society and public authorities, allowed a "social management" of public resources of Union general budget for investment and funding projects for "territorials units", i.e. sets of municipios grouped by common identity characteristics. This study aims to analyze dynamics of social management within the Borborema, Paraiba, considering history of social dynamics that allowed the emergence of a strong social movement and the establishment of a powerful union pole. These elements show high level of "social capital" in the territory before de creation of the forum. In this sense, we can understand why, despite evident progress of participatory dynamics and its positive impact on the local sociopolitical environment, territorial practices have, however, an "institutional performance" below of expectations in relation to few investment projects effectively implemented between 2003 and 2010.

Key words: Social Capital; Territories; Institutional Performance

MÁRCIO CANIELLO: Professor Associado da UFCG, Coordenador da Célula de Acompanhamento e Informação da Borborema, Paraíba. E-mail: caniello@ufcg.edu.br. MARC PIRAUX: Pesquisador do CIRAD, Professor Visitante da UFPA, Pesquisador Colaborador da Célula de Acompanhamento e Informação da Borborema, Paraíba. E-mail: marcpiraux@uol.com.br. VALÉRIO VERÍSSIMO DE SOUZA BASTOS: Técnico da Célula de Acompanhamento e Informação da Borborema, Paraíba. E-mail: valerioverissimo@hotmail.com. 
INTRODUÇÃO

Com a promulgação da Constituição Federal de 1988, os espaços para a participação da sociedade civil na definição e implementação das políticas públicas no Brasil ampliaramse significativamente. Resultado da própria luta pela redemocratização do país e fruto da atuação decisiva dos movimentos sociais organizados nesse processo (DOIMO, 1995; GOHN, 2001, p. 52; SANTOS e AVRITZER, 2002, p. 65), a institucionalização do chamado "controle social" sobre as políticas públicas reflete a consolidação daquilo que os cientistas políticos chamam de "democracia direta" ou "democracia participativa” (BOBBIO, 2000).

$\mathrm{O}$ pressuposto fundamental dessa concepção de democracia é que a participação direta dos cidadãos e das organizações sociais em arenas deliberativas paritárias com a representação governamental em seus diversos níveis favorece o bom desempenho das instituições públicas e a eficiência de suas políticas e ações em virtude do "controle social" exercido pela população sobre a destinação e aplicação dos recursos públicos.Por outro lado, o exercício da participação dos cidadãos nesses fóruns leva ao empoderamento da sociedade civil, à ampliação do capital social local (PUTNAM, 2006) e à própria melhoria de vida da população, em decorrência do desenvolvimento de uma "cultura cívica" (PUTNAM, 2006) construída em torno da responsabilização coletiva quanto ao desempenho das políticas públicas.

Esse modelo foi aplicado na profusa constituição de conselhos gestores de políticas públicas na década de 1990 (CARVALHO e TEIXEIRA, 2000), inclusive dos Conselhos Municipais de Desenvolvimento Rural Sustentável (CMDRS), que se multiplicaram exponencialmente a partir de 1997, depois da criação do PRONAF, cujos recursos da linha infraestrutura e serviços só poderiam ser acessados pelas prefeituras que apresentassem um Plano Municipal de Desenvolvimento Rural Sustentável (PMDRS) homologado pelo conselho.

Embora seu "potencial de transformação política" (ABRAMOVAY, 2001, p. 121) tenha dado alguns bons frutos no sentido da democratização das políticas públicas de desenvolvimento rural, os CMDRS - como de resto todos os outros conselhos setoriais - apresentaram uma série de dilemas e paradoxos que perverteriam seus objetivos mais amplos, ressaltandose seu inelutável processo de "prefeiturização" (JARA, 1998, p. 235), isto é, a submissão da agenda construída participativamente aos interesses dos grupos políticos hegemônicos nos municípios, o chamado "poder local".

Diante dessa realidade, a partir de 2003 o governo brasileiro resolveu reconfigurar o espaço de participação da sociedade civil em relação às políticas públicas para o desenvolvimento rural, adotando o "enfoque territorial de desenvolvimento rural" (ADIB, 2005), efetivamente aplicado pela Secretaria de Desenvolvimento Territorial (SDT) do Ministério do Desenvolvimento Agrário (MDA). Isso se efetivou por meio da formação de colegiados (ou fóruns) participativos paritários compos- 
tos por representantes da sociedade civil e dos governos federal, estadual e municipal ${ }^{1}$ em "instâncias territoriais", isto é, conjuntos de municípios agrupados por características identitárias comuns (OLIVEIRA, 2008). Esse processo de inovação institucional culminaria na criação do Programa Territórios da Cidadania em 2008.

Concordando com PUTNAM (2006, p. 24) que "as instituições são mecanismos para alcançar propósitos, não apenas para alcançar acordo", este trabalho visa analisar a dinâmica da gestão social no território da Borborema, na Paraíba, de maneira a verificar as relações entre o seu ideário e as consequências práticas de sua atuação, a partir da análise de questionários sobre o tema da gestão do colegiado aplicados aos seus 80 membros efetivos, dos indicadores de avaliação dos projetos de infraestrutura concluídos $^{2}$ e das impressões colhidas e sistematizadas no processo de observação participante desenvolvido desde agosto de 2010.

Considerando que o território da Borborema possui um histórico de dinâmicas sociais que favoreceram a emergência de um movimento social forte e a constituição de um combativo Polo Sindical (BASTOS, 2010), isto é, que o território apresentava um "capital social” (PUTNAM, 2006) relativamente consolidado antes mesmo da implantação do colegiado, procuramos entender porque, apesar do evidente avanço das dinâmicas participativas e de suas repercussões positivas no ambiente sociopolítico local, as práticas territoriais apresentam, contudo, um "desempenho institucional" (PUTNAM, 2006: 24) abaixo das expectativas ${ }^{3}$, vis-a-vis aos poucos projetos de investimento efetivamente implantados entre 2003 e 2010.

\section{O TERRITÓRIO DA BORBOREMA}

O Território da Borborema situa-se no Agreste paraibano e ocupa uma área de 3.233 $\mathrm{km}^{2}$ (23,1\% do Estado), com 21 municípios distribuídos em cinco microrregiões geográficas definidas pelo IBGE, cujas sedes municipais estão em média separadas umas das outros por distâncias entre 10 e 20 quilômetros, e que variam muito em área, indo de pouco mais de $25 \mathrm{~km}^{2}$ (Borborema) a $594 \mathrm{~km}^{2}$ (Campina Grande). Entretanto, podemos considerar que a grande maioria é de pequenas dimensões, pois treze municípios $(62 \%)$ têm até $200 \mathrm{~km}^{2} \mathrm{e}$

1. Arenas deliberativas em que se desenvolve a "gestão social” (OLIVEIRA e PERAFÁN, 2012). Para o MDA, os colegiados territoriais "oportunizam o diálogo, a negociação, a aprendizagem, a transparência e a democracia necessária à construção de um ambiente favorável à integração e ao estabelecimento de consensos, de acordos, ações e compromissos coletivos fundamentais ao processo de desenvolvimento" (BRASIL, 2009, p. 4). 2. Calculados pelo Sistema de Gestão Estratégica (SGE) da SDT com metodologia própria (BRASIL, 2011), a partir dos 21 questionários aplicados pela equipe de pesquisa sobre os sete projetos de investimentos concluídos no Território da Borborema até 2010. Para cada projeto foram aplicados três questionários a informantes notadamente "conhecedores": um beneficiário, um membro do colegiado e o proponente/executor. 3. "Para ter um bom desempenho, uma instituição democrática tem que ser ao mesmo tempo sensível e eficaz: sensível às demandas de seu eleitorado e eficaz na utilização dos recursos limitados para atender a essas demandas" (PUTNAM, 2006, p. 25). 
nove (43\%) até $100 \mathrm{~km}^{2}$ de área.

Segundo o IBGE (BRASIL, 2011), a população urbana é predominante no território da Borborema, mas, dos 21 municípios que o compõem, oito (38\%) apresentam uma população rural maior do que a população urbana e quinze $(71,4 \%)$ têm populações rurais superiores a 30\% dos habitantes. Entendemos que esse alto índice de população urbana deve ser relativizado, pois em função das pequenas distâncias que separam as zonas urbanas das rurais, do bom estado das estradas, do maior acesso aos meios de transporte (como as motocicletas e os “alternativos"), além do alto índice de violência rural que vem acometendo o território, muitos habitantes dividem o seu dia entre o "sítio", onde desenvolvem suas atividades produtivas e a "rua", para onde se deslocam no final do dia, para pernoitar.

Ademais, excetuando-se o município de Campina Grande, a população rural atinge o percentual de 43,81\% no território da Borborema, o que nos leva a asseverar que a economia, a cultura e as sociedades locais mantêm suas raízes profundamente imersas no ethos rural. De fato, mais de 140 mil pessoas habitam o espaço rural deste pequeno território e, afora Campina Grande, todos os municípios possuem pelo menos $1 / 4$ de população rural.

A agricultura familiar é a principal categoria produtiva do setor agropecuário territorial, pois, segundo o IBGE (2009), existem 27.564 estabelecimentos rurais no território, dos quais 24.745 (90,76\%) são de agricultores familiares. Entretanto, os menos de dez por cento de agricultores não familiares con- centram 56,88\% das terras, o que aponta, evidentemente, para uma grande concentração fundiária. Sem embargo, há casos interessantes que evidenciam a força da agricultura familiar, como o do município de Matinhas, o maior produtor de tangerina do Nordeste e de banana e laranja do Estado, onde 90\% dos estabelecimentos são de agricultores familiares, os quais ocupam 72,26\% das áreas produtivas.

A mais importante atividade agrícola do território é a fruticultura, com uma produção de 165 mil toneladas em 2006, respondendo por toda a safra de tangerina e de mudas de frutas cítricas do Estado, além de 94\% da laranja, 66\% do limão, 61\% da banana, 70\% do abacate e 61\% da jaca. Outras lavouras importantes são o feijão preto ( $45 \%$ da produção estadual), a batata inglesa $(32,6 \%)$, a fava $(27 \%)$ e a mandioca (14,4\%) (BRASIL, 2009). A horticultura também é uma atividade agrícola forte no território da Borborema, que responde por 25\% da produção do Estado, tendo colhido cerca de 30 mil toneladas no ano de 2006 (BRASIL, 2009).

Embora relativamente incipiente e concentrada em alguns municípios, a produção agroindustrial do território da Borborema apresenta alguns dados interessantes. Em primeiro lugar, o território é o maior produtor de cachaça da Paraíba, tendo destilado 1.342.000 litros em 2006, 83\% da produção estadual. Além da aguardente, outros produtos de destaque na agroindústria local são a farinha de mandioca, com 1.418 toneladas no mesmo ano (45\% da produção estadual), a polpa de frutas produzida no município de Matinhas, 60 toneladas 
(43\% da produção estadual) e os dois mil litros de suco de frutas produzidos no município de Serra Redonda (40\% da produção estadual) (BRASIL, 2009).

Como se sabe, a comercialização dos produtos agropecuários e agroindustriais é um fator fundamental para o desenvolvimento territorial. Neste sentido, a difusão de feiras agroecológicas no território da Borborema tem sido uma importante medida para o escoamento da produção e o fomento da agricultura familiar, agregando renda ao empreendimento camponês. Atualmente, existem sete feiras agroecológicas no território, comercializando uma média de 600 toneladas anuais, segundo dados do Polo Sindical da Borborema (CANIELLO $e t$ al, 2011, p. 22).

Um fator de incremento econômico que merece destaque é o processo de transferência de renda proporcionado pelas políticas públicas nos últimos anos, como a universalização da aposentadoria rural e a sua paridade com o salário mínimo, a política de valorização deste e programas sociais, como o Bolsa Família. Contudo, a pobreza no meio rural, apesar de um notável processo de redução desde o primeiro governo Lula, ainda é expressiva no território da Borborema, onde 42,51\% dos domicílios são classificados como domicílios pobres (BRASIL, 2011).

Sendo assim, excetuando-se Campina Grande pela dimensão que tem para a economia do Estado, a principal atividade econômica do território da Borborema reside na agricultura familiar. Esta atividade é fortalecida pela diversidade da produção agrícola territorial (frutas, grãos e horticultura), pelo escoamento da produção através das feiras (agroecológicas e livres), programas de compras governamentais (PAA e PNAE), e também das políticas de transferência de renda (aposentadorias, auxílios, bolsa família, seguro safra, entre outras).

\section{AS DINÂMICAS TERRITORIAIS NA BOR- BOREMA}

O território da Borborema foi "campesinizado" no Século XVII em decorrência do processo de expansão da cultura da cana-deaçúcar na Zona da Mata, o qual levou à expulsão para o Agreste de grandes contingentes dos "pobres livres" que viviam em sua órbita, criando animais e produzindo alimentos (CANIELLO et al, 2011, p. 7-8). Desde então, o território vem experimentando uma evolução histórica que alterna períodos de "descampesinização" e "recampesinização", ao sabor dos poderes da agricultura patronal e de seus interesses nos diversos "ciclos econômicos" ali desenvolvidos, em maior ou menor abrangência regional: algodão, café, cana-de-açúcar, agave, pecuária, fumo e laranja (PIRAUX e MIRANDA, 2011).

Entretanto, desde os anos 1950, os camponeses do Agreste paraibano têm mostrado

4. Para os conceitos de campesinização, descampesinização e recampesinização, ver PLOEG (2008). 
um poder de resistência e mobilização notáveis, primeiramente nas Ligas Camponesas e, depois de sua extinção pela Ditadura Militar, nos Sindicatos dos Trabalhadores Rurais (STR) e outros movimentos sociais. Não é preciso falar muito sobre isso, mas apenas evocar dois de seus mártires: João Pedro Teixeira e Margarida Maria Alves, ambos trucidados pelas elites agrárias locais.

Os doze primeiros STR reconhecidos oficialmente na Paraíba em 1962 e 1963 estão localizados no Agreste, sendo que oito deles situam-se no atual território da Borborema. Embora tenham desempenhado uma função essencialmente assistencialista durante o período da ditadura, no início dos anos 1980 inicia-se um importante processo de renovação sindical que redundaria, vinte anos depois e com o concurso de vários atores, instituições e organizações sociais, na criação do Polo Sindical e das Organizações da Agricultura Familiar da Borborema (BASTOS, 2010). O Polo atualmente congrega uma rede de 15 STRs (doze localizados no território da Borborema), aproximadamente 150 associações comunitárias e uma organização regional de agricultores ecológicos, a Ecoborborema ${ }^{5}$.

Em virtude desse processo de renovação, as pautas de luta no território, outrora tratadas de forma genérica (a exemplo da luta pela reforma agrária e pela universalização da previdência social rural), foram tomando um sentido mais "orgânico" ao conectarem-se a um projeto de futuro visando à sustentabilidade de sua diversificada agricultura familiar. Assim, o Polo, apoiado pela AS-PTA ${ }^{6}$, passa a atuar como um ator coletivo demandador de políticas públicas específicas e como um espaço político-organizativo em torno de um projeto comum de desenvolvimento local focado na promoção da agroecologia.

Com a implementação do Programa Territórios Rurais de Identidade no ano de 2003, constituiu-se formalmente o Território de Identidade da Borborema, que teve como base a existência do Território Agroecológico do Polo da Borborema, gestado desde o início dos anos 1990, que já contava com a participação da sociedade civil, mostrando capacidade de ação coletiva, iniciativas locais e, sobretudo, apresentando legitimidade e mobilização. Esse ambiente social e politicamente favorável propiciou a constituição de novas ONGs no território e a criação do Fórum dos Assentados da Borborema. Por outro lado, há que se ressaltar a existência de instituições de ensino e pesquisa no território, como a Embrapa, UFCG, UFPB e UEPB, que há muito interagem com os agricultores familiares da região em ações de ensino, pesquisa e extensão, bem como a presença de organizações nacionais e internacionais de apoio ao desenvolvimento rural.

Esse conjunto de entidades vem desenvolvendo ações que têm provocado fortes im-

\footnotetext{
5. http://aspta.org.br/programas/programa-paraiba/

6. Organização não governamental nacionalmente reconhecida por sua atuação no fortalecimento da agricultura familiar e na promoção do desenvolvimento rural sustentável no Brasil, atuante na região desde 1996. Ver http://aspta.org.br/.
} 
pactos no território, a exemplo da produção de algodão agroecológico, estocagem de forragem, tecnologias apropriadas para segurança hídrica, a criação das redes de banco de sementes e de construção do conhecimento agroecológico, iniciativas de educação no campo, entre outras.

Neste sentido, os atores inseridos no território da Borborema compartilham um conjunto de valores, conceitos e estratégias de ação, configurando-se como um ambiente de disputa de modelos, no qual as redes de inovação agroecológica apresentam-se como expressão da resistência ao modelo dominante baseado nos princípios técnico-científicos da revolução verde.

Alguns momentos comprovam a força desses atores e de suas organizações. Por exemplo, no ano de 2002, após um intenso debate em torno da qualidade, importância e resistência dos bancos de sementes, conseguiu-se aprovar a Lei Estadual 7.298/2002, que dispõe sobre a criação do Programa Estadual de Bancos Comunitários de Sementes. Em 2009, os agricultores familiares e suas organizações mobilizaram-se em face da perspectiva do avanço da fumicultura no território, promovida pela Souza Cruz, a qual realmente não prosperou na Borborema. Outro episódio de destaque aconteceu em 2010, ano em que a região do Brejo foi atingida pela mosca negra, praga da citricultura, quando foi travada uma forte disputa: de um lado, o Governo do Estado da Paraíba, que defendia o controle tradicional e que, inclusive, iniciara a distribuição de inseticidas para o combate da mosca e, de outro, os agricultores familiares ligados ao Polo, assessores e pesquisadores da UFPB, que defendiam o controle biológico, resultando vitoriosa a tese dos agricultores organizados.

Foi nesse panorama de recampesinização, transição agroecológica (DINIZ e PIRAUX, 2011) e de presença de um capital social relativamente consolidado que, em 2003, a SDT/ MDA homologou o "Território de Identidade da Borborema", transformado em "Território da Cidadania" a partir de 2008. Assim, era de se esperar um bom desempenho do colegiado territorial em termos da execução de projetos de investimento, em vista do grande interesse despertado por eles ${ }^{7}$, da disponibilização de recursos específicos para isto e do "protagonismo" dos agricultores familiares e suas organizações no processo de decisão e controle social.

Entretanto, como veremos a seguir, uma série de fatores organizacionais, institucionais e da dinâmica participativa do colegiado territorial têm dificultado essa dialética virtuosa. Este artigo pretende discutir as relações entre a presença de um capital social consolidado no território da Borborema e os resultados do chamado "ciclo de gestão social" nele desenvolvido.

7. Apuramos em nossa pesquisa de campo que o Núcleo Dirigente como um todo e muitos membros entrevistados afirmam que a principal motivação para a inserção de suas organizações ou instituições no Colegiado Territorial foi a matriz orçamentária lançada pelo governo federal. Ou seja, os atores sociais e suas organizações viram nessa matriz a oportunidade de acessar recursos para o desenvolvimento de projetos de infraestrutura que já almejavam anteriormente. 
3. O FUNCIONAMENTO DO COLEGIADO TERRITORIAL DA BORBOREMA

\section{COMPOSIÇÃO E ORGANIZAÇÃO}

À época do levantamento das informações que dão suporte a este trabalho, o colegiado da Borborema era composto por 99 membros, 80 deles em efetivo exercício ${ }^{8}$, sendo 46 representantes da sociedade civil $(57,5 \%)$ e 34 do poder público $(42,5 \%)^{9}$, o que denota seu caráter paritário e mesmo a preponderância do "controle social" no âmbito decisório. Das instituições participantes, 29 delas $(36,25 \%)$ frequentavam o colegiado há pelo menos dois anos e 40 instituições, 50\% do total, participavam há mais de três anos, registrando-se que as instituições com um maior período de participação, a exemplo dos Sindicatos de Trabalhadores Rurais, fazem parte ou são parceiras do Polo Sindical.

Com uma composição tão ampla, evidencia-se a necessidade de uma estrutura burocrática mínima para o funcionamento, o que não tem sido observado. Assim, não há um sistema eficiente de convocação dos membros para as plenárias, nem o registro e aprovação de atas das reuniões realizadas - a não ser quando estas são pré-requisitos indispensáveis para aprovação de projetos - ou mesmo a manutenção de um arquivo com documentos. É preciso ressaltar, neste sentido, que a irregularidade da manutenção do assessor territorial, bem como sua "pluriatividade" quando em efetivo exercício da função, são fatores extremamente deletérios ao ordenamento organizacional.

Outra fragilidade organizacional destacada pelos membros do colegiado é a falta de objetividade das reuniões e o longo tempo gasto nas plenárias. Um informante, em expressão que sumaria este sentimento, nos disse textualmente: "se fala muito e se produz pouco". Pudemos observar que essa falta de objetividade tem afastado várias instituições das reuniões.

\section{COMUNICAÇÃO}

Apesar da maioria dos entrevistados ter destacado a internet como o principal canal de divulgação das decisões tomadas pelo colegiado, em entrevistas informais com a equipe de pesquisa, grande parte destes membros afirmou ter dificuldade em receber essas informações. De fato, o colegiado não mantém um sítio na internet e a própria atualização dos dados no sistema "Colegiados em Rede" não tem sido efetuada. Os membros do colegiado explicam essa fragilidade pela ausência de um processo eficiente de acompanhamento, como também pelo fato do colegiado não possuir sequer uma

8. Os quais foram entrevistados e formam a base de dados aqui analisada.

9. Segundo dados do SGE, atualmente o Colegiado tem 111 membros, sendo 68 da sociedade civil (61\%) e 43 do poder público (39\%), um núcleo dirigente com oito representantes, um núcleo técnico e várias câmaras temáticas. http://sge.mda.gov.br/cr/cr_re/. 
lista de e-mails atualizada, o que faz com que um número significativo dos próprios membros não tenha acesso e desconheça as decisões tomadas pelo colegiado, e que seja bastante limitada a socialização de documentos, como atas, relatórios, prestações de contas e deliberações da coordenação.

De mais a mais, como foi apurado na pesquisa sobre as condições de vida da população do território, numa amostra aleatória de 235 famílias entrevistadas, distribuídas em dez setores censitários, 94\% afirmaram não possuir computador, o que evidentemente demonstra que a escolha da forma de divulgação das decisões do fórum participativo não é das mais adequadas.

Contudo, a falta de conhecimento das decisões e ações do colegiado pode ser atribuída pela não participação e pela rotatividade de vários membros, como se pode observar no Gráfico 1, mas, de fato, não existe uma estratégia de comunicação no colegiado e mesmo nas instituições e organizações participantes.

Assim, podemos afirmar, com base nos dados apurados e na observação participante efetuada pela equipe de pesquisa, que o processo de articulação, comunicação e circulação de informações entre a coordenação do colegiado e seus membros, bem como com a população do território, é bastante precária.

\section{PARTICIPAÇÃO E DECISÃO}

Segundo os membros do colegiado, a baixa participação dos gestores públicos nas re- uniões, sobretudo prefeitos e vice-prefeitos, destacada por 56 entrevistados (70\%), tem sido o problema que mais prejudica o seu desempenho, pois, segundo eles, determinadas decisões só podem ser tomadas com a presença dos gestores, como por exemplo, a doação de um terreno ou o cumprimento de contrapartidas para a realização dos projetos. Seguindo a escala de importância, aparece o problema da baixa participação dos produtores, lembrado por 52 deles (65\%), o que evidencia que a participação dos agricultores é feita, sobretudo, por mediadores e a alta rotatividade dos membros, ressaltada por 41 respondentes (51\%). Numa escala de 1 a 5 , sendo 1 "muito baixa" e 5 "muito alta" a média obtida por cada problema que afeta o colegiado está expressa no Gráfico abaixo, que demonstra serem as fragilidades da participação efetiva os fatores mais deletérios.

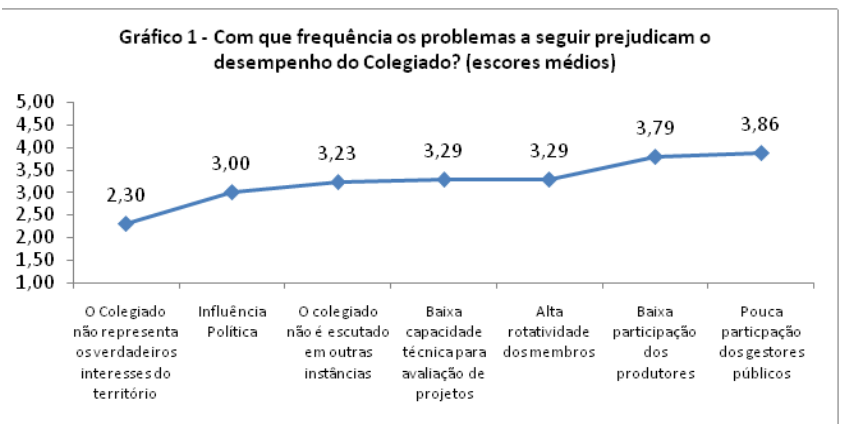

Fonte: Elaboração própria com dados tabulados pelo SGE/ SDT/MDA/CAI - 2011

Em relação à capacidade de tomada de decisões, destacam-se os representantes das associações e sindicatos, lembrados por $70 \%$ dos entrevistados como tendo capacidade "alta" e "muito alta", depois aparecem os represent- 
antes dos agricultores familiares, com 66,3\% e os representantes das organizações não governamentais destacados por $62,5 \%$. Ainda foram lembrados por mais da metade dos membros (47) os representantes dos movimentos sociais.

Por outro lado, a capacidade de decisão dos representantes dos governos municipais foi definida como "baixa" ou "muito baixa" por 30 membros (37,5\%), ao passo que $27,5 \%$ dos respondentes tiveram a mesma avaliação quanto aos representantes das universidades e $26,3 \%$ em relação aos representantes do governo estadual. A baixa capacidade de decisão atribuída a esses membros está relacionada principalmente ao absenteísmo e à rotatividade de representantes da esfera governamental.

Numa escala de 1 a 5 , sendo 1 "capacidade de decisão muito baixa" e 5 "capacidade de decisão muito alta", a média obtida pelos representantes das entidades que compõem o colegiado territorial da Borborema, segundo os entrevistados, foram as que estão expressas no Gráfico 2.

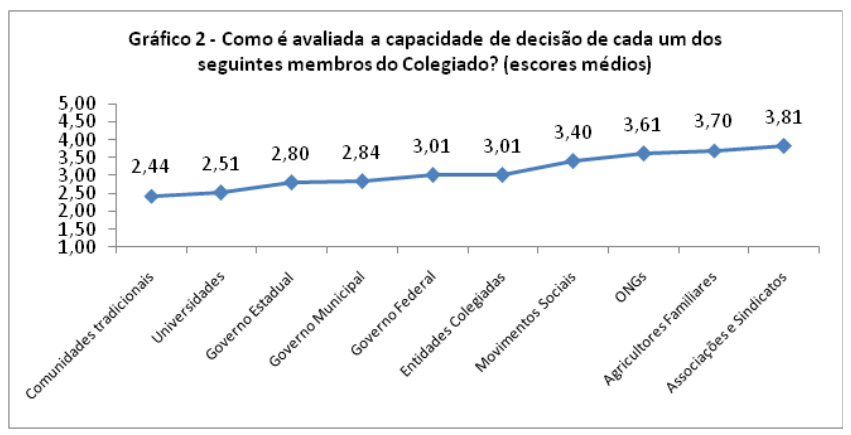

Fonte: Elaboração própria com dados tabulados pelo SGE/ SDT/MDA/CAI - 2011

A qualidade da participação e a pre- eminência das decisóes de alguns atores na dinâmica territorial estão ligadas às ações existentes no território antes mesmo da constituição do colegiado, notadamente as dinâmicas do Polo Sindical da Borborema e da AS-PTA, organizações que, juntamente com outras que se constituíram posteriormente, como a ONG Arribaçã, formam o "núcleo duro" (PIRAUX e BONNAL, 2009) do colegiado territorial. Esse grupo hegemônico foi construído em torno de princípios ideológicos e interesses compartilhados sobre o desenvolvimento rural e seu "empoderamento" deve-se à consolidação do seu capital social ao longo dos últimos anos através da recepção de recursos financeiros para execução de projetos, primeiramente oriundos de instituições internacionais e, a partir de 2003, também do governo federal, o que reforça seus capitais simbólico e político.

Assim, apesar da composição do colegiado primar pela distribuição da representação social entre as várias organizações presentes no território, esse "núcleo duro" possui força suficiente para conduzir o debate e a pauta ${ }^{10}$. De fato, vários informantes qualificados afirmam que as informações são monopolizadas e as ações são concentradas, planejadas e decididas por esse "núcleo duro", o que realmente pode ser confirmado quando se analisa a distribuição de recursos alocados pelo MDA para os projetos de infraestrutura.

De fato, é notória a disparidade de acesso aos projetos de investimento destinados pelas matrizes orçamentárias do MDA para o território da Borborema em favor de municípios sob a influência direta do "núcleo duro" e em 
detrimento de outras edilidades, pois dos 21 municípios que o compõem, apenas 10 receberam investimentos em infraestrutura, todos eles localizados na sua "zona central”, área de atuação do Polo Sindical (CANIELLO et. al., 2011, p. 132).

Se, por um lado, podemos considerar que a estratégia montada pelo grupo hegemônico seja legítima, pois atende às regras pré-estabelecidas do campo democrático e reflete a preeminência dos setores mais organizados nas deliberações por maioria (BOURDIEU, 2007), ele é também um fator deletério, pois acaba marginalizando exatamente os setores representativos mais fracos em termos de capital social, reproduzindo sua situação de fragilidade e desestimulando a participação dos seus representantes. Neste sentido, representantes de municípios alijados do acesso a recursos para projetos de investimento, como Borborema, Pilões e Serraria deixaram de participar das reunióes, cuja justificativa formulada por um de seus representantes é lapidar: "só se debate coisa de interesse do Polo... quando é coisa de interesse das prefeituras ou de outra instituição que não faz parte do Polo, elas não querem debater".

É importante salientar, ademais, que $86,4 \%$ dos respondentes afirmaram que as deliberações são tomadas pelo critério da votação por maioria, enquanto apenas $31 \%$ ressaltaram os acordos por consenso. Essa preeminência da "maioria" como critério de decisão evidentemente favorece grupos de interesse hegemônicos em detrimento de minorias, o que é um fator de marginalização destas, principalmente se consideramos a diversidade intraterritorial.

\section{DOCUMENTOS ORIENTADORES}

Um traço característico quanto à elaboração de documentos de diagnóstico e de planejamento pelo colegiado é que existe uma tendência decrescente quando se vai do campo das ideias para o campo da prática (Ver Gráfico 3). Podemos verificar essa tendência quando analisamos, por exemplo, a participação das entidades na elaboração de instrumentos de planejamento para a intervenção prática no desenvolvimento territorial. Em primeiro lugar, o total de participações em todas as fases de elaboração dos documentos (oficinas de discussão, concepção e elaboração, e revisão) decresce de 112 no diagnóstico para 110 no PTDRS e 101 no documento com a "visão de futuro". Isto é, a participação das entidades na elaboração dos documentos diminui em termos gerais, decrescendo da elaboração do documento que registra a percepção da realidade ("diagnóstico"), ao instrumento de planejamento de curto prazo, inclusive necessário para a liberação de recursos para os projetos (o PTDRS) e, mais ainda, à elaboração de um documento de planejamento de longo prazo ("visão de futuro").

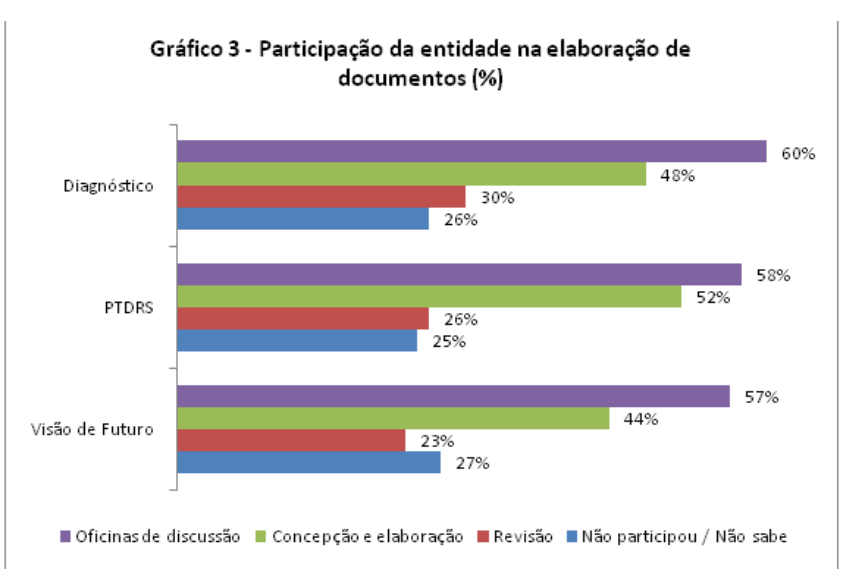

Fonte: Elaboração própria com microdados do SGE/SDT/MDA/ CAI - 2011 
Por outro lado, a participação das entidades no processo de construção do Diagnóstico, do Plano Territorial de Desenvolvimento Rural Sustentável (PTDRS) e da Visão de Futuro decresce significativamente quando se passa da participação nas "oficinas de discussão para sua formação" para as fases de "concepção e elaboração" dos documentos e, finalmente sua "revisão", que é a chamada fase de "qualificação" dos instrumentos. Ou seja, a participação é maior quando os documentos são discutidos nas inúmeras “oficinas” promovidas e menor quando se trabalha efetivamente na sua elaboração concreta. Por exemplo, no ano de 2010, a reunião do colegiado que tinha como pauta a revalidação do PTDRS contou com a participação de menos de 20 dos membros, isto é, menos de $25 \%$ do quórum.

O próprio Resumo Executivo do PTDRS do território da Borborema 2010-2020, elaborado pela ONG Vínculus e publicado pelo MDA (BRASIL, 2010) denuncia essa tendência, pois, das 62 páginas, 52 são dedicadas ao diagnóstico territorial e apenas oito ao planejamento estratégico, limitado a um diagrama (p. 53) e uma planilha (pp. 54-60) com os "eixos aglutinadores", "programas", "projetos" e “ações”. Não há sequer um plano de metas, um cronograma de ações e/ou projetos e, muito menos, instrumentos de verificação com indicadores de resultados esperados. Assim, como um "Plano Territorial de Desenvolvimento Rural Sustentável", o documento resume-se a uma extensa introdução contextual e um vago conjunto de boas intenções.

Um dado associado a essa tendência se refere às áreas em que os membros do colegiado receberam capacitação. Conforme pudemos apurar (CANIELLO et al., 2011, p. 77), os membros do colegiado afirmaram ter participado de 239 capacitações, conjunto que podemos estratificar em três grupos, indo de propostas mais teóricas a propostas mais práticas, a saber: (1) qualificação em planejamento do desenvolvimento rural ("planejamento participativo", “desenvolvimento territorial" e "planejamento estratégico"), que totalizam 103 capacitações (43\%); (2) elaboração de projetos e planos de desenvolvimento, com 52 ocorrências (22\%); e (3) intervenção nos processos de desenvolvimento ("controle social”, “organização", "monitoramento e avaliação" e "gestão de conflitos"), com 84 ocorrências (35\%). Isto é, 65\% das capacitações foram voltadas para o planejamento e a elaboração de projetos, enquanto apenas $35 \%$ para a preparação dos membros do colegiado quanto à efetivação desses projetos e planos, sua gestão e controle.

Assim, percebemos que ainda existe um hiato significativo entre as ideias planejadas e debatidas no colegiado e o processo de colocar em prática e acompanhar estas ações. Mas, se as praticas têm que ser melhoradas, fica necessário progressivamente voltar no campo das ideias, perguntando-se sobre a natureza dessas ideias e, sobretudo compartilhar elas entre todos os participantes, passo necessário para definir uma real estratégia comum de desenvolvimento. 


\section{PROJETOS DE INVESTIMENTO}

Segundo o MDA/SDT, os projetos de investimentos são propostas técnicas com metas específicas que podem ser apoiadas com recursos de investimentos em obras, empreendimentos, máquinas, equipamentos e outros bens necessários para o fortalecimento da agricultura familiar, com destaque para os aspectos econômicos, sociais, culturais, todos coerentes com o PTDRS (BRASIL, 2011b).

De acordo com os participantes do colegiado, o debate em torno dos projetos tem sido o ponto alto da gestão social no território da Borborema e as plenárias que tratam dessa temática apresentam maior índice de presença. Contudo, a frequência do debate em torno dos projetos não reflete a dinâmica de execução dos mesmos, pois atualmente, a maioria dos projetos de investimentos que foram deliberados pelo colegiado ainda não foi entregue às comunidades.

De fato, em oito anos de funcionamento do colegiado territorial (2003-2010) foram aprovados 16 projetos de infraestrutura, totalizando R\$ 3.348.428,67 em investimentos, sendo que nove estão concluídos, dois atrasados, três paralisados e dois não iniciados (Ver Tabela Anexa). Embora 56\% dos projetos contratados estejam concluídos, neles foram empregados pouco mais de 770 mil reais, o que representa apenas $23 \%$ dos recursos destinados a obras de infraestrutura e aquisição de equipamentos no território da Borborema (Gráfico 4).

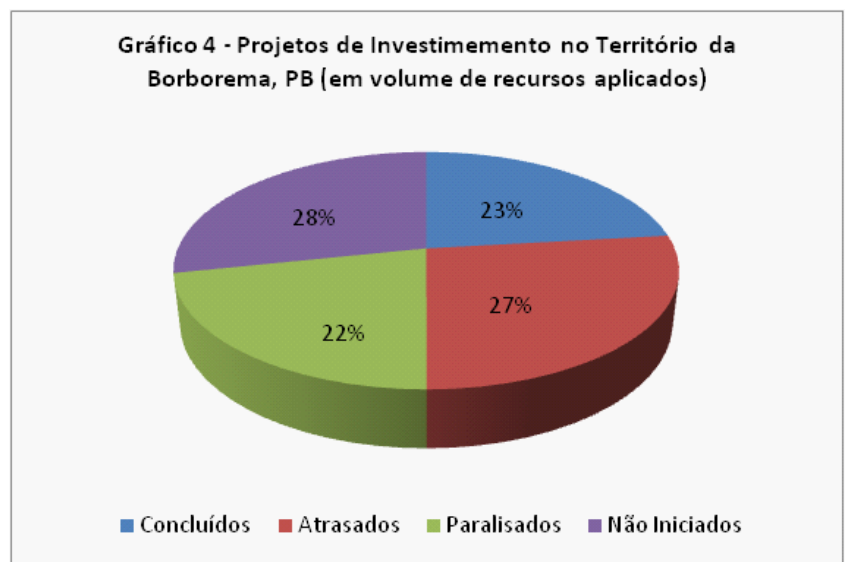

Fonte: elaboração própria com dados do SGE/SDT/MDA/CAI (posição em 31/12/2012)

Dos projetos concluídos, seis foram contratados nos anos de 2003 e 2004 e são focados em obras de segurança hídrica (cisternas de placas e barragens subterrâneas), sendo que um deles também contemplou a construção de um Mercado do Produtor no município de Montadas. Os outros três projetos concluídos tinham como objeto: (1) aquisição de veículo utilitário e equipamentos de informática (Massaranduba); (2) construção e aquisição de equipamentos para viveiro de mudas e aquisição de máquina debulhadeira (Alagoa Nova) e (3) aquisição de máquinas e equipamentos para estruturação de um núcleo de beneficiamento de forragem (São Sebastião de Lagoa de Roça).

Dos projetos paralisados, um é executado pela Prefeitura Municipal de Campina Grande e encontra-se em Tomada de Contas Especial, outro, executado pelo governo do Estado, tem como objeto a construção de um centro de apoio à mandiocultura em Puxinanã e o terceiro refere-se à implantação de uma unidade móvel de extração de mel em Alagoa 
Nova.

Estão atrasados os projetos de aquisição de máquinas debulhadeiras e forrageiras ${ }^{11}$, também executado pelo governo do Estado, e a construção e estruturação do Centro de Vivência com o Curimataú, sob a responsabilidade da Prefeitura Municipal de Arara. Ainda não foram iniciadas as obras de implantação de uma biofábrica para produção de palma forrageira e da Casa Família Agrícola, ambos executados pelo governo do Estado, sendo o primeiro pela Secretaria de Desenvolvimento da Agropecuária e da Pesca (SEDAP) e o segundo pela Universidade Estadual da Paraíba (UEPB), cujos recursos foram liberados em 2008.

Os membros do colegiado alegam que a ineficiência na execução dos projetos territoriais na Borborema acontece em função da baixa capacidade técnica do colegiado, da baixa participação dos beneficiários (a exemplos dos prefeitos) e dos entraves impostos pela burocracia institucional. De fato, as normas de gestão dos financiamentos públicos, pouco adaptadas aos objetivos dos projetos coletivos, dificultam muito a definição e implementação de projetos de infraestrutura para as áreas rurais (LEITE e WESZ, 2010; BONNAL e KATO, 2010).

Seja como for, procuramos investigar detalhes sobre sete projetos de investimento concluídos, todos eles referentes a obras de segurança hídrica e, realizados com recursos das matrizes orçamentárias de 2003 e 2005, por meio de pesquisa de opinião ${ }^{12}$, em que foram coletadas informações sobre o planejamento, a execução, a gestão e a avaliação de resultados dos projetos concluídos. A partir de tabulação de dados, foram gerados indicadores referentes a essas quatro fases, classificados a partir da seguinte escala: ótimo $(0,80-1,00)$, bom $(0,60-0,80)$; regular $(0,40-0,60)$; ruim $(0,20$ $-0,40)$ ou crítico $(0,0-0,20)$.

De acordo com os resultados obtidos (Gráfico 5), percebe-se que todos os indicadores apontam para escores bastante baixos, sendo três deles (planejamento, gestão e impacto) classificados como "ruim" e a execução dos projetos classificada como "regular".

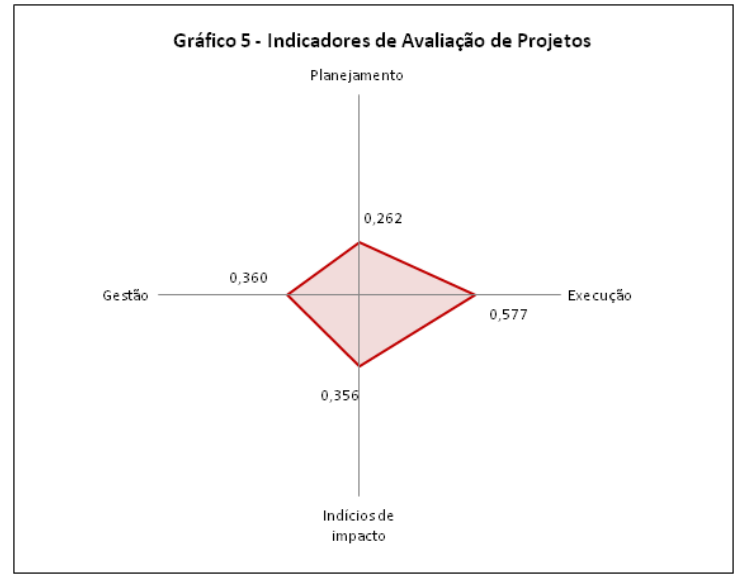

Fonte: MDA/SDT/SGE/CAI

11. Embora as máquinas tenham sido adquiridas, o projeto como um "empreendimento" não foi plenamente concluído, uma vez que as máquinas forrageiras que foram destinadas aos Sindicatos de Trabalhadores Rurais encontram-se em atividade, mas as máquinas debulhadeiras que foram destinadas às Prefeituras não foram sequer localizadas pela equipe de pesquisa. Em função de suas características especiais, este projeto está sendo analisado com maior profundidade e será tratado em um artigo específico. 12. Pesquisa realizada no primeiro semestre de 2011, quando estavam concluídos 7 projetos. Foram 21 entrevistados (para cada projeto foi aplicado um mesmo questionário para três "conhecedores": um beneficiário, um membro do colegiado e o proponente). 
O indicador "planejamento" obteve o pior índice $(0,262)$, apontando que a participação de beneficiários, membros do colegiado e até proponentes nesta fase ocorreu de forma bastante insatisfatória, uma vez que 42,9\% dos entrevistados não sabem sequer como ocorreu sua definição, 23,8\% afirmam que o projeto "foi ofertado pela SDT-MDA" e absolutamente nenhum deles disse que o mesmo estava previsto no PTDRS.

O indicador "execução dos projetos" atingiu o escore de 0,577, sendo classificado como "regular", e foi a fase melhor avaliada pelos entrevistados. Este indicador estima: (1) a participação dos beneficiários na fase de execução dos projetos, que atingiu o escore de 0,560 ; (2) a capacidade de execução $(0,534)$; e (3) o nível de funcionamento dos mesmos, o quesito melhor avaliado, com uma média de 0,638, classificando-o como "bom", o que é um dado alentador neste panorama extremamente negativo, pois aponta para a eficácia dos projetos concluídos.

No que tange à "gestão dos projetos", que obteve um índice de 0,36, "baixo", 38,1\% dos informantes afirmaram não saber sequer como ele se caracteriza e mais da metade dos respondentes disse não saber se existe algum tipo de auditoria ou acompanhamento financeiro dos projetos. Os dados revelam ainda que a maioria dos entrevistados (61,9\%) não tem conhecimento sobre os indicadores de acompanhamentos do projeto.

Quanto aos "indícios de impacto" dos projetos, a avaliação atingiu o escore de 0,356 , sendo também considerada "ruim", mas quan- do perguntados sobre os efeitos deles na qualidade de vida dos beneficiários, $42,9 \%$ dos respondentes responderam que ela "melhorou" ou "melhorou muito" em decorrência dos projetos, atingindo-se um escore de 0,591 para o quesito "impactos positivos na qualidade de vida dos beneficiários", no limite entre "regular" e "bom". Também para 42,9\% dos respondentes os projetos concluídos "atenderam" ou "superaram" as expectativas.

Portanto, embora apresentando falhas no planejamento, execução e gestão dos projetos concluídos, o seu nível de funcionamento e os impactos positivos deles na vida dos beneficiários foram considerados satisfatórios.

\section{CONSIDERAÇÕES FINAIS}

Mesmo concordando com PETERSEN e SILVEIRA (2007) que a consolidação do território da Borborema tem uma trajetória evolutiva oscilante e não linear, o fato é que há anos ali se verifica um notável processo de mobilização e organização social em torno dos projetos que endogenamente os agricultores e suas organizações escolhem como adequados, o que pontuaria para uma hipotética eficiência dos sujeitos territoriais no encaminhamento de suas decisões para implementá-los. Entretanto, embora os projetos concluídos sejam relativamente bem avaliados, eles representam apenas $23 \%$ do total dos investimentos alocados ao território da Borborema, o que aponta para um certo paradoxo entre o potencial do capital social presente nas dinâmicas territoriais e seus 
resultados efetivos para o desenvolvimento territorial. Pensamos que cinco ordens de limites e constrangimentos institucionais alimentam esse paradoxo.

A primeira ordem de fatores é constituída por limites organizacionais: a falta de uma estrutura administrativa estável redunda em improvisações no que tange a procedimentos básicos, como a convocação de reuniões, redação de atas, prestações de contas, atualização de cadastros e listas de endereços, manutenção de um arquivo atualizado e a própria comunicação entre a coordenação, os membros do colegiado e a sociedade.

A segunda ordem de fatores tem a ver com os limites na participação dos membros do colegiado, em face do absenteísmo e da rotatividade dos mesmos, principalmente os representantes do poder público, ocasionada pela alternância no poder e mesmo por mudanças ocasionais no curso de um mesmo governo. Isso é um grande problema, uma vez que a imensa maioria dos recursos orçamentários destinados aos projetos é executada pelas prefeituras.

No que tange à participação da sociedade civil, também se verificam casos de rotatividade dos membros e irregularidade na participação, explicados, principalmente, por falhas de comunicação entre a coordenação e os membros do colegiado. Por outro lado, que podemos definir como "assembleísmo" - isto é, a ocorrência de muitas reuniões, frequentemente pouco produtivas e longas em função da falta de capacidade técnica e de decisão - é outro elemento que dificulta a participação dos representantes da sociedade civil. Além disso, a morosidade na execução dos projetos e a burocracia envolvida no seu encaminhamento são fatores deletérios à participação destes membros, sendo para eles um elemento de desmotivação.

A terceira ordem de fatores refere-se a constrangimentos procedimentais e tem a ver com a construção interna de regras de funcionamento do colegiado e de seu aprimoramento em favor da otimização da participação e mobilização de todos os sujeitos sociais envolvidos, inclusive os grupos minoritários. É o caso, por exemplo, do modo de tomada de decisão. Uma instância deliberativa democrática e participativa não pode simplesmente ser movida pela "ditadura" da maioria, por mais legítimos que sejam os grupos hegemônicos que a constituam, pois esses processos tendem a fortalecer estes grupos e provocar a marginalização de grupos mais fracos ou marginais, inclusive afastando-os da arena participativa. Nos parlamentos, por exemplo, as minorias têm prerrogativas importantes para evitar que os grupos majoritários imponham suas decisões de maneira sistemática, como os institutos do trancamento de pauta, da obstrução etc. De fato, a hegemonia de grupos de interesse bem articulados nas decisões do colegiado em detrimento de grupos minoritários menos poderosos - exatamente aqueles que pouco podem contar com as chamadas "assessorias", aliás, financiadas com recursos da própria matriz de recursos do território - fazem com que o "empoderamento" da sociedade civil seja seletivo e, o que é pior, um fator de marginalização dos grupos com menor "capital social". 
Assim, a construção de acordos seria mais democrática e mais produtiva no fortalecimento da identidade coletiva, da cooperação mútua e da reciprocidade, pois as votações por maioria tendem a cristalizar desigualdades e provocar segmentações, numa estratégia de desenvolvimento que se pretende igualitária, mobilizadora e cooperativa. Neste sentido, a cultura do consenso deveria ser mais promovida, a partir da qualificação do debate e da promoção de uma reflexão comum, o que poderia "empoderar" o colegiado como um todo e não apenas os grupos com capitais social, político e simbólico mais consolidados.

A quarta ordem de constrangimentos institucionais é normativa. A falta de estatuto jurídico do colegiado limita sua capacidade de ação. Sem reconhecimento jurídico, o colegiado é desprovido de uma burocracia específica e depende das Municipalidades ou de organizações não governamentais para o acesso a recursos. São fóruns deliberativos constituídos por camponeses, mas eles dependem de mediadores para executar suas deliberações. Assim, o colegiado é envolvido por estruturas políticopartidárias e técnicas e as burocracias a elas associadas, as quais drenam recursos e submetem os camponeses a suas agendas. Assim, o pretendido protagonismo dos camponeses no "ciclo de gestão social" é obstaculizado por sua dependência a mediadores, sejam eles políticos ou técnicos, do governo ou de ONGs.

Finalmente, a quinta ordem de fatores refere-se a constrangimentos ideológicos e pontua para a preeminência das ideias sobre as práticas, dos meios sobre os fins, da execução sobre o planejamento e da luta política sobre a mobilização produtiva.

Não pode haver dúvida de que o ciclo de gestão social no território da Borborema propiciou importantes avanços em termos da capacidade de aprendizagem dos atores locais, da mobilização coletiva em torno de um projeto de desenvolvimento rural sustentável, do empoderamento do capital social vinculado à agricultura familiar, de mudanças no jogo político local e de intervençóes, embora limitadas, na infraestrutura produtiva e de segurança hídrica. A perenidade e evolução desse processo virtuoso dependem, contudo, da superação dos limites e constrangimentos que o inibem, exigindo uma franca autocrítica de todos os envolvidos, desde os sujeitos e organizações territoriais até as burocracias governamentais nos três níveis federativos. 


\section{ANEXO 1 - RELAÇÃO DOS PROJETOS DE INVESTIMENTO NO TERRITÓRIO DA BOR- BOREMA (2003-2010)}

\begin{tabular}{|c|c|c|c|c|c|c|c|}
\hline Ano & $\begin{array}{l}\text { Código } \\
\text { Operação }\end{array}$ & Proponente & Objeto & Falor & $\begin{array}{l}\text { Situação } \\
\text { da Obra }\end{array}$ & Início & Conclusão \\
\hline 2003 & 0157103-73 & PM Areial & $\begin{array}{l}\text { - Construção de Cisterna de Placas } \\
\text {-Kit p/ de Cisterna de Placas } \\
\text { - Construção de Barragem Subterrânea }\end{array}$ & $30.028,26$ & Concluída & $30 / 06 / 2004$ & $18 / 03 / 2005$ \\
\hline 2003 & $0157148-71$ & PM Esperança & $\begin{array}{l}\text { - Construção de Cisterna de Placas } \\
\text { - Kit p/ de Cisterna de Placas } \\
\text { - Construção de Barragem Subterrânea }\end{array}$ & $43.120,26$ & Concluída & $01 / 07 / 2004$ & $02 / 07 / 2008$ \\
\hline 2003 & $0157151-38$ & $\begin{array}{l}\text { PM São Sebastião de } \\
\text { Lagoa de Roça }\end{array}$ & $\begin{array}{l}\text { - Construção de Cisterna de Placas } \\
\text { - Kit p/ de Cisterna de Placas } \\
\text { - Construção de Barragem Subterrânea }\end{array}$ & $41.852,83$ & Concluída & $02 / 07 / 2004$ & $28 / 12 / 2006$ \\
\hline 2003 & $0157156-80$ & PM Montadas & $\begin{array}{l}\text { - Construção de Cisterna de Placas } \\
\text { - Kit p/ de Cisterna de Placas } \\
\text { - Construção de Barragem Subterrânea } \\
\text { - Construção do Mercado do Produtor } \\
\end{array}$ & $234.580,53$ & Concluída & $02 / 07 / 2004$ & $22 / 09 / 2006$ \\
\hline 2004 & $0163690-78$ & PM Alagoa Nova & $\begin{array}{l}\text { - Construção de Cisterna de Placas } \\
\text { - Kit p/ de Cisterna de Placas }\end{array}$ & $30.202,21$ & Concluída & $21 / 01 / 2005$ & $02 / 12 / 2005$ \\
\hline 2004 & 0163691-82 & $\begin{array}{l}\text { PM Campina } \\
\text { Grande }\end{array}$ & $\begin{array}{l}\text { - Construção de Cisterna de Placas } \\
\text { - Kit p/ de Cisterna de Placas } \\
\text { - Construção de Barragem Subterrânea } \\
\text { - Feira Agroecológica }\end{array}$ & $103.596,24$ & $\begin{array}{l}\text { Paralisada } \\
\text { Tomada de } \\
\text { Contas } \\
\text { Especial }\end{array}$ & $25 / 08 / 2005$ & \\
\hline 2004 & 0163694-13 & PM Remígio & $\begin{array}{l}\text { - Construção de Cisterna de Placas } \\
\text { - Kit p/ de Cisterna de Placas } \\
\text { - Construção de Barragem Subterrânea }\end{array}$ & $33.098,44$ & Concluída & $18 / 01 / 2006$ & $15 / 05 / 2007$ \\
\hline 2005 & 0176541-41 & PM Massaranduba & $\begin{array}{l}\text { - Aquisição de veiculo utilitário } \\
\text {-Equipamentos de informática }\end{array}$ & $54.508,70$ & Concluída & $26 / 12 / 2006$ & $15 / 06 / 2007$ \\
\hline 2005 & 0177408-40 & PM Alagoa Nova & $\begin{array}{l}\text { - Construção e aquisição de equipamentos } \\
\text { para viveiro de mudas } \\
\text { •Aquisição de máquina debulhadeira. }\end{array}$ & $99.313,69$ & Concluída & $02 / 02 / 2007$ & $02 / 03 / 2011$ \\
\hline 2005 & 0177593-92 & SEDAP & $\begin{array}{l}\text { - Aquisição de máquinas para beneficia } \\
\text { mento de Arroz, Milho e Feijão } \\
\text { - Aquisição de máquinas de beneficiamento } \\
\text { e armazenamento de forragem }\end{array}$ & $217.557,00$ & Atrasada & $26 / 06 / 2006$ & \\
\hline 2006 & 0197575-99 & SEDAP & $\begin{array}{l}\text { - Aquisição de máquinas para beneficia } \\
\text { mento de Arroz, Milho e Feijão } \\
\text { • Aquisição de máquinas de beneficiamento } \\
\text { e armazenamento de forragem }\end{array}$ & $503.800,00$ & Paralisada & $26 / 02 / 2008$ & \\
\hline 2007 & $0229256-25$ & PM Arara & $\begin{array}{l}\text { - Construção e estruturaçãa do Centro de } \\
\text { Vivência com o Curimataú } \\
\text { - Implantação Base de Serviço e Apoio à } \\
\text { Comercializacão da Agricultura Familiar }\end{array}$ & $679.307,33$ & Atrasada & $02 / 07 / 2008$ & \\
\hline 2008 & $0278178-05$ & SEDAP & $\begin{array}{l}\text { - Implantação de Biofábrica de mudas de } \\
\text { palma forrageira }\end{array}$ & 398.951 .18 & Não Iniciada & & \\
\hline 2008 & $0282725-03$ & UEPB & $\begin{array}{l}\text {-Construção de uma Escola Família do } \\
\text { Campo (Lagoa Seca) }\end{array}$ & $549.300,00$ & Não Iniciada & & \\
\hline 2008 & $0282747-62$ & $\begin{array}{l}\text { PM São Sebastião } \\
\text { de Lagoa de Roça }\end{array}$ & $\begin{array}{l}\text { - Aquisição de máquinas e equipamentos } \\
\text { para estruturação do Núcleo de Beneficia- } \\
\text { mento de Forragem }\end{array}$ & $209.694,00$ & Concluída & $30 / 12 / 2010$ & $27 / 07 / 2012$ \\
\hline 2009 & $0306600-32$ & PM Alagoa Nova & $\begin{array}{l}\text {-Implantação de unidade móvel de extração } \\
\text { de mel }\end{array}$ & $119.518,00$ & Paralisada & $03 / 08 / 2011$ & \\
\hline \multicolumn{4}{|c|}{ TOTAL } & 3.348 .42 & & & \\
\hline
\end{tabular}

Fonte: Sistema de Gestão Estratégica (SGE) - MDA/SDT - 2011, com atualização até 23/11/2012. 


\section{REFERÊNCIAS BIBLIOGRÁFICAS}

ABRAMOVAY, Ricardo. "Conselhos além dos limites", Estudos Avançados, vol. 15, $\mathrm{n}^{\mathrm{O}}$ 43, 2001, pp. 121-140.

ADIB, Alberto Renault. Plano Territorial de Desenvolvimento Rural Sustentável: guia para planejamento. Brasília, IICA Brasil, 2005.

BOBBIO, Norberto. O futuro da democracia: uma defesa das regras do jogo. Rio de Janeiro, Paz e Terra, 2000.

BASTOS, V. V. S. Uma nova prática de ação sindical: o caso do Polo Sindical da Borborema - Paraíba.Dissertação de mestrado. UFCG/CH/ PPGCS. Campina Grande, 2010. 115 f.

BONNAL, P. e KATO, K. Análise comparativa de politicas públicas de desenvolvimento territorial. Relatório de Pesquisa. OPPA/CPDA/ UFRRJ. Brasília: IICA, 2010.

BRASIL.Censo Agropecuário 2006. Brasília, IBGE, 2009. < http://www.sidra.ibge.gov.br >

.Censo Demográfico Brasileiro 2010. Brasília， IBGE，2011. < http://www. sidra.ibge.gov.br>

- Orientação para constituição e $\overline{\text { funcionamento }}$ dos colegiados territoriais. Brasília, MDA, 2009b.

. Sistema de Gestão Estratégica: Avaliação de Projetos de Investimentos. Brasília, MDA/SDT, 2011b.

- Territórios da Cidadania -
Relatório de Execução 2008: Ações executadas no Território da Cidadania Borborema (PB). Brasília, Ministério do Desenvolvimento Agrário / Secretaria de Desenvolvimento Territorial, 2010. Disponível em: <http://www. territoriosdacidadania.gov.br/> . Acesso em: 10 março 2011.

BOURDIEU, Pierre. O Poder Simbólico. Tradução de Fernando Tomaz,11a Edição. Rio de Janeiro, Bettrand Brasil, 2007.

CANIELLO, M.; PIRAUX, M.; MARTINS, M.F.; BASTOS, V.V.S. Acompanhamento, Monitoramento e Avaliação da Evolução e Qualidade dos Resultados do Programa Desenvolvimento Sustentável de Territórios Rurais - PDSTR no Território da Borborema (Paraíba). Projeto de Pesquisa para o Edital MDA/SDT/CNPq - Gestão de Territórios Rurais No. 05/2009. Campina Grande, GEPAD/UFCG, 2009.

CANIELLO, M.; BASTOS, V.V.S.; MARTINS, M.F.; PIRAUX, M., CANTALICE, L.; NUNES, T.L.; TORRES, J.V.O. Relatório Analítico do Projeto de Pesquisa Acompanhamento, monitoramento e avaliação da evolução e qualidade dos resultados do Programa Desenvolvimento Sustentável dos Territórios Rurais - PDSTR no Território da Borborema (Paraíba). Campina Grande, GEPAD/UFCG; Brasília, SGE/SDT/ MDA, 2011.

CANIELLO, M.; BASTOS, V.V.S.; CANTALICE, L.; "Análise de desempenho do Programa Territórios da Cidadania: o caso do Orçamento 2008 do Território da Borborema-PB". In GEHLEN, V.R.F.; LAINÉ, P.C.V. (orgs.) Construindo com fios invisíveis: a fragmentação do território rural. Recife, Editora da UFPE, 2012. 
CARVALHO, Maria do Carmo A. A. e TEXEIRA, Ana Claudia C. (Org.) Conselhos Gestores e Políticas Públicas. São Paulo, Pólis, 2000.

DINIZ, P.C.O., PIRAUX, M. Agroecologia e convivência com o semiárido: Breves notas de uma longa trajetória de diálogo e interfaces. InLIMA, J.R.Tavares de (org.): Agroecologia e movimentos sociais. Recife, Edições Bagaço, 2011.

DOIMO, A. M. A vez e a voz do popular: Movimentos Sociais e participação politica no Brasil pós-70. Rio de Janeiro,Relume-Dumará/ANPOCS, 1995.

GOHN, Maria da Glória. Conselhos gestores e participação sociopolitica. São Paulo, Cortez, 2001.

IBGE. Censo demográfico 2010. Disponível em: < http://www.ibge.gov.br >. Acesso em: 06 abril 2011.

JARA, Carlos Júlio. A sustentabilidade do desenvolvimento local. Brasília, IICA; Recife, Secretaria de Planejamento do Estado de Pernambuco, 1998.

LEITE, S. P. e WEIZ, W. J. Jr. Financiamento das politicas de financiamento territorial. Relatório final. OPPA/CPDA/UFRRJ.Brasília: IICA, 2010.

OLIVEIRA, Carlos Douglas de Sousa; PERAFÁN, Mireya Eugenia Valencia. Gestão social no âmbito do Programa Desenvolvimento Sustentável de Territórios Rurais. Anais do $5^{\circ}$ Encontro da Rede de Estudos Rurais. CD ROM (ISBN 978-85-63737-02-1). Belém, junho de
2012.

OLIVEIRA, José Humberto: Programa 'Territórios da Cidadania': uma estratégia de desenvolvimento territorial e garantia de direitos sociais voltados para as regiões de maior fragilidade socioeconômica. Anais do XIII Congreso Internacional del CLAD sobre la Reforma del Estado y de la Administración Pública. Buenos Aires, Argentina, 2008.

PETERSEN, P; SILVEIRA, L. Construção do conbecimento agroecológico em redes de agricultores-experimentadores: a experiência de assessoria ao Polo Sindical da Borborema. In: Construção do conhecimento agroecológico: novos papéis, novas identidades. Rio de Janeiro, ANA, 2007.

PIRAUX, M; BONNAL, P. Projetos coletivos de desenvolvimento territorial no entorno de Campina Grande (PB): O elo faltante da multifuncionalidade da agricultura familiar.In: Agricultura familiar: multifuncionalidade e desenvolvimento territorial no Brasil. Ademir A. Cazella, Philippe Bonnal e Renato S. Maluf organizadores.Rio de Janeiro: Mauad X, 2009.

PIRAUX, Marc e MIRANDA Roberto. A longa emergência da agricultura familiar: relações entre atividade agrícola, atores sociais e formas de intervenção do estado no Agreste paraibano. Raízes: Revista de Ciências Sociais e Econômicas. Vol. 30, No 2 - Jul-Dez de2010. Campina Grande, 2011.

PLOEG, Jan Douwe van der. Camponeses $e$ impérios alimentares: lutas por autonomia $e$ sustentabilidade na era da globalização. Porto Alegre, Editora da UFRGS, 2008. 
PUTNAM, Robert D. Comunidade e Democracia: a experiência da Itália modernal com Robert Leonardi e Raffaella Y. Nannetti; tradução de Luiz Alberto Monjardim. $5^{\text {a }}$ edição, Rio de Janeiro, Editora Fundação Getúlio Vargas, 2006.

SANTOS, Boaventura de S.\& AVRITZER, Leonardo: "Introdução: para ampliar o $c \hat{a}$ none democrático", SANTOS, Boaventura de S.(org.), Democratizar a democracia: os caminhos da democracia participativa.Rio de Janeiro, Civilização Brasileira, 2002. 